\title{
Characterization of Tio2 And An As-Prepared Tio2/Sio2 Composite And Their Photocatalytic Performance For The Reduction Of Low- Concentration N-NO3- In Water
}

\author{
Wanzhen Zhong \\ Shandong Agricultural University \\ Weizhang Fu ( $\nabla$ sdaufwz@sdau.edu.cn ) \\ Shandong Agricultural University https://orcid.org/0000-0002-2629-1091 \\ Shujuan Sun \\ Shandong Agricultural University \\ Lingsheng Wang \\ Shandong Agricultural University \\ Huaihao Liu \\ Shandong Agricultural University \\ Junzhi Wang \\ Qingdao University of Technology
}

\section{Research Article}

Keywords: low-concentration N-NO3-, TiO2, TiO2/SiO2, Photocatalysis, Reduction reaction, Nitrogen conversion rate

Posted Date: December 14th, 2021

DOI: https://doi.org/10.21203/rs.3.rs-1027427/v1

License: (c) (i) This work is licensed under a Creative Commons Attribution 4.0 International License. Read Full License 
Characterization Of Tioz And An As-Prepared Tion/Sion 2 Composite And Their Photocatalytic Performance For The Reduction Of Low-Concentration $\mathrm{N}-\mathrm{NO}_{3}{ }^{-}$

In Water

\section{Environmental Science and Pollution Research}

Wanzhen Zhong ${ }^{1,2}$, Weizhang Fu ${ }^{* 1}$, Shujuan Sun*1 ${ }^{* 1}$ Lingsheng Wang ${ }^{1}$, Huaihao Liu ${ }^{1}, J u n z h i$

Wang $^{2}$

1. College of Resources and Environment, Shandong Agricultural University, Tai'an, 271018, PR

China

2. School of Environmental and Municipal Engineering, Qingdao University of Technology,

* Co-corresponding author: 
Abstract:Excessive $\mathrm{N}_{-} \mathrm{NO}_{3}{ }^{-}$water pollution has become a widespread and serious problem that threatens human and ecosystem health. Here, a $\mathrm{TiO}_{2} / \mathrm{SiO}_{2}$ composite photocatalyst was prepared via the sol-gel/hydrothermal method. $\mathrm{TiO}_{2}$ and $\mathrm{TiO}_{2} / \mathrm{SiO}_{2}$ were characterized by $\mathrm{X}$-ray diffraction (XRD), UV-Vis differential reflectance spectroscopy (DRS), Fourier infrared (FT-IR) spectroscopy, X-ray photoelectron spectroscopy (XPS), scanning electron microscopy (SEM), and energy-dispersive X-ray spectroscopy (EDS). Afterward, the photocatalytic performance of $\mathrm{TiO}_{2}$ and $\mathrm{TiO}_{2} / \mathrm{SiO}_{2}$ to reduce low nitrate concentrations $\left(30 \mathrm{mgN} \cdot \mathrm{L}^{-1}\right)$ under UV light were evaluated and the effects of different factors on this process were investigated, after which the reaction conditions were optimized. Removal rates of up to $99.93 \%$ were achieved at a hole scavenger (formic acid) concentration of $0.6 \mathrm{~mL} \cdot \mathrm{L}^{-1}$, a $\mathrm{CO}_{2}$ flow rate of $0.1 \mathrm{~m}^{3} \cdot \mathrm{h}^{-1}$, and a $\mathrm{TiO}_{2}$ concentration of $0.9 \mathrm{~g} \cdot \mathrm{L}^{-1}$. In contrast, $\mathrm{TiO}_{2} / \mathrm{SiO}_{2}$ at a $1.4 \mathrm{~g} \cdot \mathrm{L}^{-1}$ concentration and $\mathrm{TiO}_{2}$ load rate of $40 \%$ achieved a removal rate of $83.48 \%$, But with more than $98 \%$ of nitrogen generation rate. $\mathrm{NO}_{2}{ }^{-}$and $\mathrm{NH}_{4}{ }^{+}$were the minor products, whereas $\mathrm{N}_{2}$ was the main product.

\section{Keywords: low-concentration $\mathrm{N}_{-} \mathrm{NO}_{3} ; \mathrm{TiO}_{2} ; \mathrm{TiO}_{2} / \mathrm{SiO}_{2} ;$ Photocatalysis; Reduction reaction;}

\section{Nitrogen conversion rate}

\section{Introduction}

Water is a vital and often limiting resource for the development of human society. Urban sewage seepage, industrial wastewater infiltration, agricultural pesticides, and fertilizer application all contribute greatly to the exacerbation of $\mathrm{N}^{-\mathrm{NO}_{3}}{ }^{-}$groundwater pollution, and this has become a serious environmental issue worldwide. In addition to being chemically stable, $\mathrm{N}_{-} \mathrm{NO}_{3}{ }^{-}$is highly water-soluble and mobile, making it difficult to remove from water environments (Velu et al. 2021). This compound poses a serious risk to human and environmental health and has been linked to teratogenicity and carcinogenicity, in addition to the eutrophication of water bodies and land salinization (Ghafari et al.

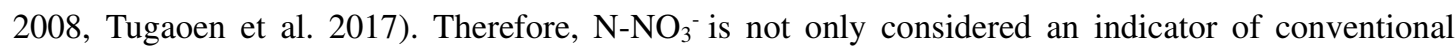
water quality but is also classified as a toxicological indicator. According to the World Health 
Organization and the European Union, the concentration of $\mathrm{N}_{-} \mathrm{NO}_{3}{ }^{-}$in drinking water should not exceed 10 and $11.3 \mathrm{mg} / \mathrm{L}$, respectively.

Biological denitrification, a common water treatment method, requires the introduction of a carbon source, and the temperature and carbon to nitrogen ratio of this reaction must be carefully controlled (Yao et al. 2020). Further, the rapid aging of ion exchange membranes for physicochemical denitrification leads to high costs and, in addition to not fully removing nitrate, this method produces high concentrations of saline wastewater (Gao et al. 2019). Moreover, the reaction conditions of chemical reductive denitrification cannot be easily controlled and are prone to hydrogen and oxygen evolution and other side reactions, resulting in secondary environmental pollution (Garcia-Segura et al. 2018). In contrast, photocatalysis by semi-conductors is a novel and environmentally friendly method for $\mathrm{N}_{-} \mathrm{NO}_{3}{ }^{-}$removal that is highly selective toward $\mathrm{N}_{2}$, has fast reduction kinetics and a small footprint, and does not generate sludge.

Velu et al. (2021) reported $\mathrm{N}^{-\mathrm{NO}_{3}}{ }^{-}$removal rates of up to $94 \%$ via photocatalysis using an

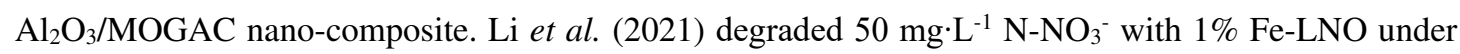
UV light. After $120 \mathrm{~min}$, the optimized nitrate removal rate reached $86.69 \%$ and the optimized $\mathrm{N}_{2}$ selectivity was $85.71 \%$. Bi et al. (2021) evaluated the degradation of nitrogen oxide catalyzed by $\mathrm{TiO}_{2} / 0.25 \mathrm{Nb}_{2} \mathrm{O}_{5}$ under visible light and achieved a removal rate of $77.23 \%$. Liu et al. (2021)reported that $\mathrm{Ag}_{3} \mathrm{Pd}_{7} / \mathrm{g}-\mathrm{C}_{1.95} \mathrm{~N}_{4}$ exhibited the highest photocatalytic activity and selectivity for the photocatalytic reduction of $\mathrm{NO}_{3}{ }^{-}$and $\mathrm{NO}_{2}^{-}$under $25^{\circ} \mathrm{C}$ and $365 \mathrm{~nm}$ irradiation, and the removal rates of $\mathrm{NO}_{3}{ }^{-}$and $\mathrm{NO}_{2}^{-}$were $87.4 \%$ and $61.8 \%$, respectively. Hou et al. (2021) prepared 5 wt $\% \mathrm{Ag} / \mathrm{SiO}_{2} @ \mathrm{cTiO}_{2}$ and reported that the nitrate removal rate and $\mathrm{N}_{2}$ selectivity were respectively $95.8 \%\left(\mathrm{C}_{0}=2000 \mathrm{mg} / \mathrm{L}\right)$ and 93.6\% after $4 \mathrm{~h}$. Wang et al. (2021) prepared $10 \mathrm{wt} \% \mathrm{SiW}_{9} / \mathrm{TiO}_{2} / \mathrm{Cu}$ and reported that the $\mathrm{N}^{-\mathrm{NO}_{3}}{ }^{-}\left(\mathrm{C}_{0}=\right.$ $30 \mathrm{mgN} / \mathrm{L}$ ) removal rate and the $\mathrm{N}_{2}$ selectivity were respectively $76.53 \%$ and $82.09 \%$ after UV radiation for $6 \mathrm{~h}$.

$\mathrm{TiO}_{2}$ has good photo-responsive performance with a band gap energy of $3.2 \mathrm{eV}$ and can utilize radiation with wavelengths less than $390 \mathrm{~nm}$. $\mathrm{TiO}_{2}$ becomes excited when it is irradiated with light at wavelengths higher than its band gap energy, after which the excited electrons $\left(\mathrm{e}^{-}\right)$in the valence band migrated to the conduction band. This process forms highly active negatively charged electrons and leaves positively charged holes $\left(\mathrm{h}^{+}\right)$in the valence band, resulting in electron-hole pairs. The resulting 
electrons and holes are strong oxidizing and reducing agents, which can degrade many pollutants when irradiated with light ( $\mathrm{Lv}$ et al. 2019). In addition to its excellent optical properties, $\mathrm{TiO}_{2}$ has become a popular catalyst for the photocatalytic reduction of $\mathrm{N}_{-} \mathrm{NO}_{3}{ }^{-}$due to its non-toxicity, stability, and low cost (Li et al. 2019, Tsang et al. 2019, Yang et al. 2004).

For water treatment purposes, $\mathrm{TiO}_{2}$ must be easily separated and recovered. Therefore, this compound is routinely modified by coating and is immobilized on a substrate to separate it from the treated water more effectively (Woottikrai et al. 2022). Typical coating modification methods mainly include electrochemical, hydrothermal, sol-gel, and chemical precipitation methods, among which the sol-gel method is the most common.

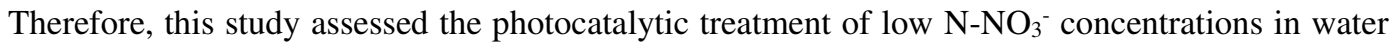
using $\mathrm{TiO}_{2}$. Further, to recycle the $\mathrm{TiO}_{2}$, a sol-gel method was used to coat and immobilize it on $\mathrm{SiO}_{2}$ to obtain a $\mathrm{TiO}_{2} / \mathrm{SiO}_{2}$ composite catalyst. Particularly, three aspects were systematically evaluated in this study: (a) the effects of different factors (catalyst dose, catalyst loading rate, hole scavenger dose, and

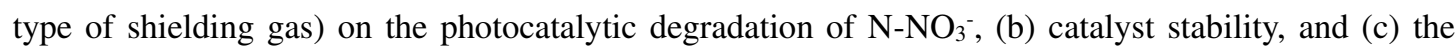
mechanism of photocatalytic reduction of $\mathrm{N}_{-} \mathrm{NO}_{3}{ }^{-}$by $\mathrm{TiO}_{2}$ and the $\mathrm{TiO}_{2} / \mathrm{SiO}_{2}$ composite.

\section{Materials and methods}

In addition to $\mathrm{TiO}_{2}$ nanoparticles, this study also evaluated a $\mathrm{TiO}_{2} / \mathrm{SiO}_{2}$ composite by loading different proportions of $\mathrm{TiO}_{2}$ on the surface of $\mathrm{SiO}_{2}$ particles. The photocatalytic reduction of $\mathrm{N}_{-} \mathrm{NO}_{3}{ }^{-}$ under UV light was simulated indoors.

\subsection{Preparation of the $\mathrm{TiO}_{2} / \mathrm{SiO}_{2}$ composite catalyst}

$\mathrm{SiO}_{2}$ particles were immersed in a $\mathrm{NaOH}$ solution $(\mathrm{pH}=10)$ and sonicated for $2 \mathrm{~h}$ to increase their surface roughness. Nanoparticle composites were generated using the sol-gel hydrothermal synthesis method (Jesus et al. 2021, Takari et al. 2021, Wang et al. 2017). Solution A was prepared by slowly adding $10 \mathrm{~mL}$ of butyl titanate to $20 \mathrm{~mL}$ of absolute ethanol, followed by $1.8 \mathrm{~mL}$ of glacial acetic acid while constantly stirring the mixture. Solution B was prepared by mixing $20 \mathrm{~mL}$ of absolute ethanol with $2 \mathrm{~mL}$ of distilled water. Solution B was then added drop by drop to A solution with rapid stirring and butyl titanate was slowly hydrolyzed with continued stirring until it formed a solvate. Different amounts of $\mathrm{SiO}_{2}$ particles were added and sonicated to further hydrolyze the butyl titanate. Once $\mathrm{SiO}_{2}$ 
was evenly dispersed, it was transferred to an autoclave with polytetrafluoroethylene (PTFE) at $200{ }^{\circ} \mathrm{C}$ for $2 \mathrm{~h}$. The filtrate was then allowed to cool to room temperature and washed with water and ethanol until it became clear, after which it was dried at $60{ }^{\circ} \mathrm{C}$ to obtain a catalyst powder. Composite catalysts with different $\mathrm{TiO}_{2}$ loads were then obtained (loading = mass of $\mathrm{TiO}_{2} /$ total mass of catalyst).

\subsection{Sample characterization}

$\mathrm{TiO}_{2}$ nanoparticles, the $\mathrm{TiO}_{2} / \mathrm{SiO}_{2}$ composite catalyst, and the recovered (i.e., used in a reaction cycle) catalysts were characterized to study their morphology, structure, photochemical properties, and chemical stability.

\subsubsection{Characterization by scanning electron microscopy (SEM)}

Samples were characterized by SEM (20,000x, Hitachi S4800) and energy-dispersive X-ray spectroscopy (EDS) (HORIBA 7593-H) to examine their morphology and microstructure.

\subsubsection{Characterization by X-ray diffraction (XRD)}

An X-ray diffractometer (XRD, Ultima IV Advanced Diffractometer, CuKal) was used to analyze the crystal structure of the samples within a $10^{\circ}-80^{\circ}$ range at a $5^{\circ} /$ min scanning speed. The samples were then evaluated based on their characteristic peaks.

\subsubsection{Characterization by UV-Vis differential reflectance spectroscopy (DRS)}

The photocatalysts were then examined via the UV-Vis diffuse reflectance test using a spectrophotometer (Lambda $750 \mathrm{~S}, 200-800 \mathrm{~nm}$ ) and the results were used to evaluate the light absorption performance of the catalysts.

\subsubsection{Characterization by Fourier infrared (FT-IR) spectroscopy}

FT-IR tests were performed with a Bruker Vertex 70 FT-IR spectrophotometer within a 400-4000 nm wavelength range.

\subsection{Photocatalytic reduction of $\mathrm{N}-\mathrm{NO}_{3}{ }^{-}$}

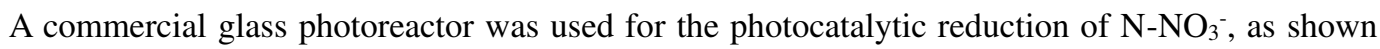
in Fig. 3. The experimental light source was a $125 \mathrm{w}$ high-pressure mercury lamp with a primary wavelength of $365 \mathrm{~nm}$, and the device was equipped with an external water cooling system to ensure a 
constant reaction temperature. For each experiment, $500 \mathrm{~mL}$ of $\mathrm{KNO}_{3}\left(\mathrm{C}_{0}=30 \mathrm{mgN} / \mathrm{L}\right)$ solution was added to the reactor, after which predetermined amounts of catalyst and hole scavenger (formic acid) were sequentially added with constant stirring. The reaction solution was continuously purged with shielding gas to eliminate the oxygen from the device. The UV lamp was turned on $30 \mathrm{~min}$ prior to the experiment, after which the reaction solution was collected with a syringe every hour and filtered through a $0.22 \mu \mathrm{m}$ membrane. The concentrations of ammonia nitrogen, nitrate nitrogen, and nitrite nitrogen were then measured separately. Higher removal rates and superior catalytic performance were obtained at lower $\mathrm{N}^{-\mathrm{NO}_{3}}{ }^{-}$residual concentrations. Further, higher $\mathrm{N}_{2}$ production and selectivity were observed at lower ammonia nitrogen and nitrite nitrogen production levels.

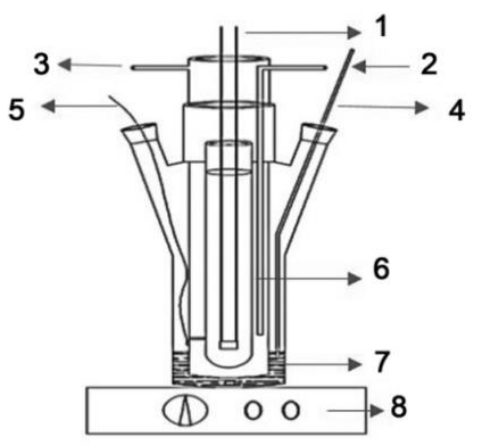

Fig. 1 Photocatalytic reaction setup: (1) UV light source; (2) water inlet; (3) water outlet; (4) air pump; (5) sampling port; (6) quartz cold trap; (7) reaction solution; (8) magnetic stirrer

\subsection{Determination of indicators}

\subsubsection{Measurement of indicators}

$\mathrm{N}-\mathrm{NO}_{3}{ }^{-}$was determined via dual-wavelength UV spectrophotometry (HJ/T 346-2007), nitrite nitrogen was determined via N-(1-naiyl)-ethylenediamine spectrophotometry (GB 7493-87), and ammonia nitrogen was determined via Nessler's reagent spectrophotometry (HJ 535-2009).

2.4.2 $\mathrm{N}_{2}$ removal rate and conversion rate calculations

$$
\mathrm{N}-\mathrm{NO}_{3}{ }^{-} \text {removal rate }=\left(\mathrm{C}_{0}-\mathrm{C}_{1}\right) / \mathrm{C}_{0} \times 100 \%
$$

$\mathrm{N}_{2}$ selectivity $=\left(\mathrm{C}_{0}-\mathrm{C}_{1}-\mathrm{C}_{2}-\mathrm{C}_{3}\right) /\left(\mathrm{C}_{0}-\mathrm{C}_{1}\right) \times 100 \%\left(\mathrm{~N}_{2}\right.$ selectivity refers to the proportion of $\mathrm{N}_{2}$ in

$$
\text { the product) }
$$

where $\mathrm{C}_{0}$ refers to the initial $\mathrm{N}^{-\mathrm{NO}_{3}}$ concentration in the solution; $\mathrm{C}_{1}, \mathrm{C}_{2}, \mathrm{C}_{3}$ represent the 


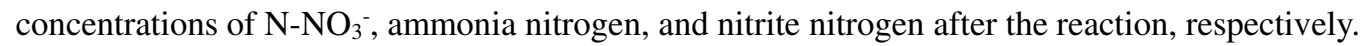

\section{Results and Discussion}

\subsection{Sample characterization}

\subsubsection{Crystal structure}

The crystal structures of catalysts before and after the reactions were investigated by XRD and FT-IR. Figs. 2 and 3 illustrate the XRD and FT-IR spectra of the catalysts before and after the reactions, respectively. As shown in Fig. 2 , the diffraction angle $(2 \theta)$ of the sample in the $10^{\circ}-80^{\circ}$ range was consistent with the spectra of anatase $\mathrm{TiO}_{2}$ (JCPDS No. 21-1272). Further, the $2 \theta$ diffraction peaks at $26.7^{\circ}, 36.6^{\circ}, 47.98^{\circ}, 53.2^{\circ}, 54.04^{\circ}$, and $62.86^{\circ}\left(\mathrm{TiO}_{2} / \mathrm{SiO}_{2}\right.$ at $2 \theta=25.44^{\circ}, 38.1^{\circ}, 48.16^{\circ}, 54.72^{\circ}, 55.16^{\circ}$, and $63.0^{\circ}$ ) correspond to the (101), (004), (200), (105), (211), (204) crystalline surfaces of anatase $\mathrm{TiO}_{2}$, respectively, indicating that $\mathrm{TiO}_{2}$ in the as-prepared composite maintained the anatase structure (Li et al. 2018, Yu et al. 2014).

The peak shapes and peak positions of the XRD spectra of the catalysts before and after the reactions were largely equal, and the crystalline structure of anatase did not change, indicating that the structure of the catalysts prepared by this method did not change significantly before and after the reactions. However, some of the reactants adsorbed on the sample surface during the reaction process wakened the intensity of some characteristic peaks after the reaction.

As illustrated in Fig. 3, the catalysts exhibited IR absorption peaks at 3343, 1632, 1435, 1061, and $933 \mathrm{~cm}^{-1}$ before and after the reactions. The absorption peak at $3343 \mathrm{~cm}^{-1}$ corresponded to the $\mathrm{O}-\mathrm{H}$ bond stretching vibrations caused by water and hydroxyl groups adsorbed on the $\mathrm{TiO}_{2}$ surface, whereas the peaks at 1632,1435 , and $443 \mathrm{~cm}^{-1}$ were characteristic of $\mathrm{TiO}_{2}$. The very weak Ti-O-Si absorption peaks of $\mathrm{SiO}_{2}$ at 1061 and $933 \mathrm{~cm}^{-1}$ indicated that $\mathrm{TiO}_{2}$ and $\mathrm{SiO}_{2}$ were mainly physically bound (i.e., as opposed to chemically bound), which mainly changed the physical properties of the catalysts. However, the introduction of $\mathrm{SiO}_{2}$ weakened the $\mathrm{TiO}_{2}$ peak (Najafidoust et al. 2019, Yao et al. 2020).

The grain size of the catalysts was calculated using the Debye-Scherrer Equation:

$$
D=k \lambda /[\cos \theta(\beta \div 180) \times 3.14]
$$


where $k$ is the Scherrer constant (the cubic particle constant $k$ is 0.943 ), $\lambda$ is the $\mathrm{Cu} \mathrm{k} \alpha 1$ incident wavelength $(\lambda=0.15406 \mathrm{~nm}), \theta$ is the diffraction angle, and $\beta$ is the full half-maximum width. The full half-maximum width was calculated in radians and the strongest diffraction peak (101) of the catalysts was used to calculate the grain size. Table 3 summarizes the results of these calculations. Smaller catalyst grains possess a larger specific surface area and therefore have better photocatalytic performance and stronger redox ability (Lucchetti et al. 2017). Similarly, the electrons photogenerated by $\mathrm{TiO}_{2}$ reach the catalyst surface more quickly when the catalyst grains are smaller, which reduces the electron-hole recombination rates and improves catalytic performance (Satayeva et al. 2018). Similarly, the solubility of the recovered catalysts increased due to the quantum size, and the catalytic performance was reduced by recrystallization in water during use, which led to an increase in crystal size.

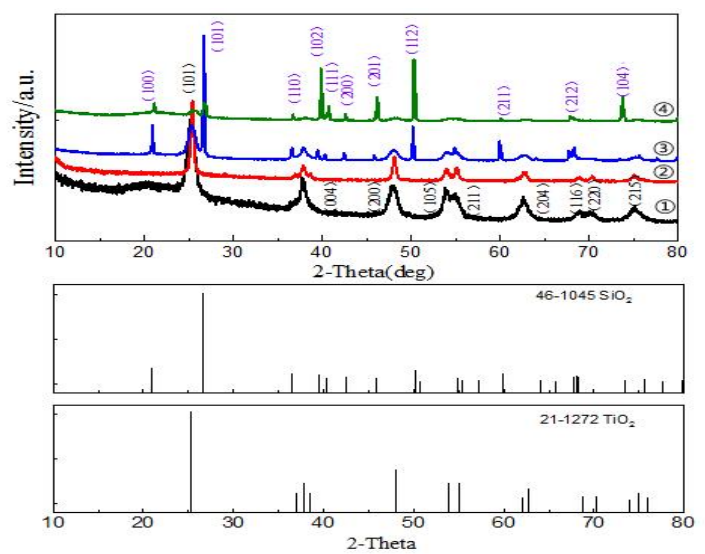

Fig. 2 XRD spectra of (1) $\mathrm{TiO}_{2}$, (2)recovered $\mathrm{TiO}_{2}$, (3) $\mathrm{TiO}_{2} / \mathrm{SiO}_{2}$, (4) recovered $\mathrm{TiO}_{2} / \mathrm{SiO}_{2}$, and $\mathrm{TiO}_{2}$ compared to the XRD standard spectra of $\mathrm{SiO}_{2}$

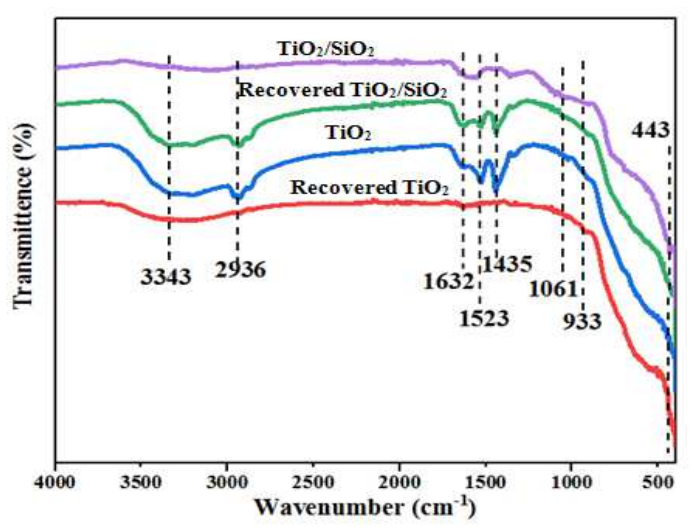

Fig. 3 FT-IR spectra of $\mathrm{TiO}_{2}$, recovered $\mathrm{TiO}_{2}, \mathrm{TiO}_{2} / \mathrm{SiO}_{2}$, and recovered $\mathrm{TiO}_{2} / \mathrm{SiO}_{2}$ at $400-4000 \mathrm{~cm}^{-1}$ 


\begin{tabular}{cccc}
\hline Photocatalyst & $\beta$ & $\theta\left(^{\circ}\right)$ & Size $(\mathrm{nm})$ \\
\hline $\mathrm{TiO}_{2}$ & 0.987 & 12.612 & 8.7 \\
recovered $\mathrm{TiO}_{2}$ & 0.976 & 12.675 & 9.4 \\
$\mathrm{TiO}_{2} / \mathrm{SiO}_{2}$ & 1.048 & 12.726 & 7.8 \\
recovered $\mathrm{TiO}_{2} / \mathrm{SiO}_{2}$ & 0.947 & 12.605 & 8.6 \\
\hline
\end{tabular}

190

\subsubsection{Morphology and structure}

The morphology and microstructure of the catalysts were investigated by SEM. Fig. 4(a) A-D shows representative SEM images (10000x) of $\mathrm{TiO}_{2}$, recovered $\mathrm{TiO}_{2}, \mathrm{TiO}_{2} / \mathrm{SiO}_{2}$, and recovered $\mathrm{TiO}_{2} / \mathrm{SiO}_{2}$, respectively. As illustrated in the figure, the catalysts exhibited spherical structures with heterogeneous sizes, and the recovered catalyst particles were slightly larger (Nguyen \&Nguyen 2009). The elemental composition of the samples was determined via EDS mapping, and these results further confirmed whether the composite was successfully synthesized. As shown in Fig. 6 (b) and (c), Ti and $\mathrm{O}$ were uniformly distributed in $\mathrm{TiO}_{2}$, whereas $\mathrm{Ti}, \mathrm{Si}$, and $\mathrm{O}$ were uniformly distributed in $\mathrm{TiO}_{2} / \mathrm{SiO}_{2}$.

The SEM images of samples demonstrated that the two catalysts were spherical in shape and similar in size both before and after the reactions. This was consistent with the results of XRD and the Debye-Scherrer Equation calculations, which further validated the stability of the samples.

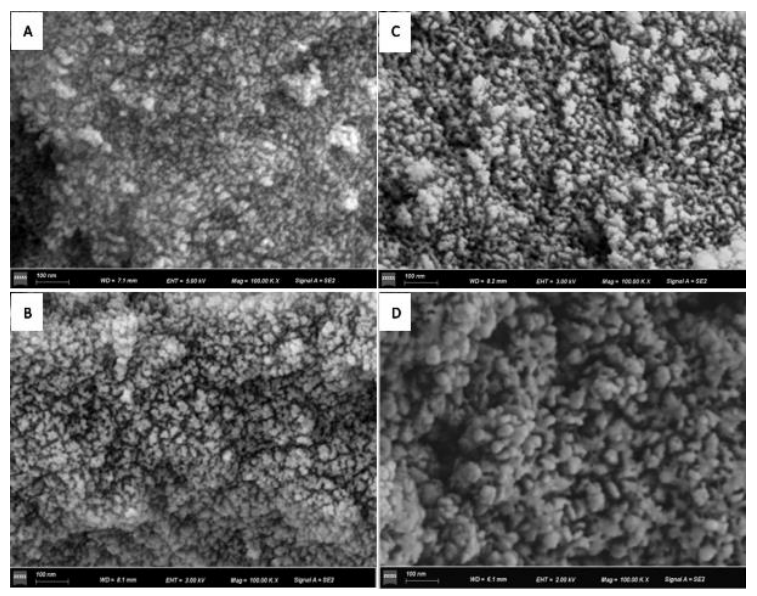




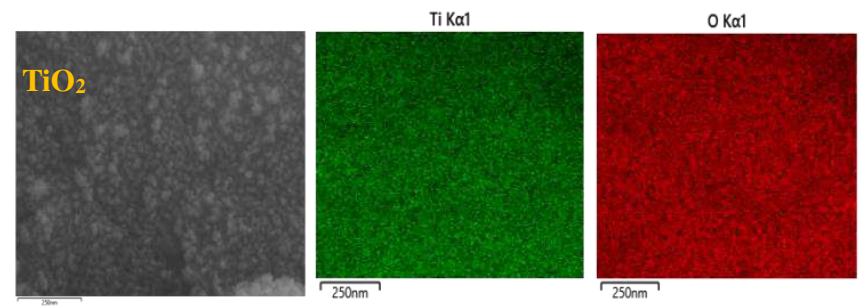

204
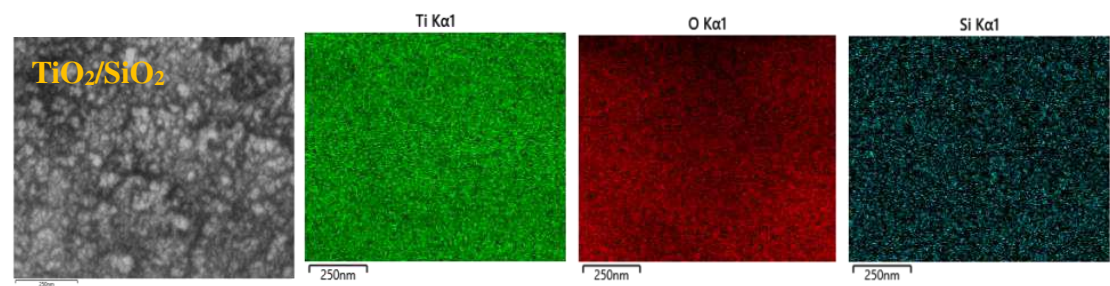

(b) Mapping
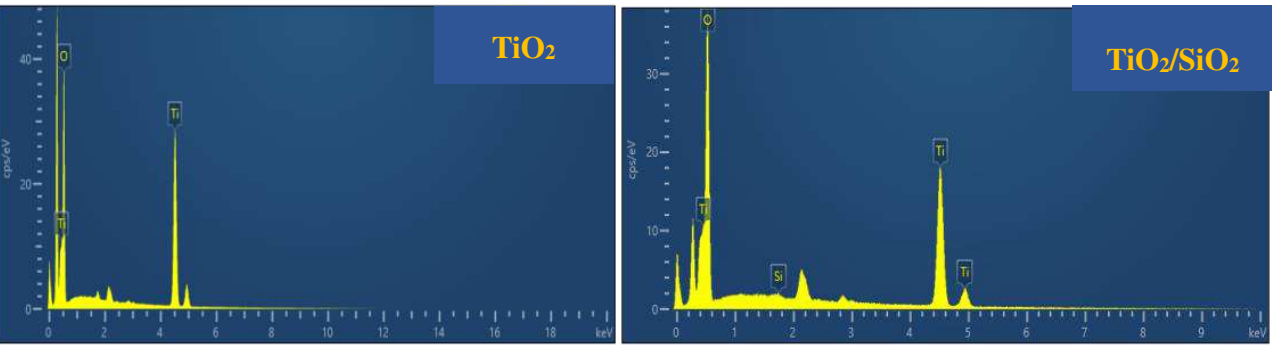

(C) EDS spectra

Fig. 4 (a; A-D) Representative SEM images (10000x) of $\mathrm{TiO}_{2}$, recovered $\mathrm{TiO}_{2}, \mathrm{TiO}_{2} / \mathrm{SiO}_{2}$, and recovered $\mathrm{TiO}_{2} / \mathrm{SiO}_{2}$, respectively; (b) elemental mapping of the two samples; (c) EDS spectra of the two samples

\subsubsection{Optical performance and band gap energy}

The optical performance of a photocatalyst is a key feature that directly affects the photocatalytic activity of the materials. Fig. 5 (a) shows the UV-Vis DRS absorption spectra of $\mathrm{TiO}_{2}$, recovered $\mathrm{TiO}_{2}$, $\mathrm{TiO}_{2} / \mathrm{SiO}_{2}$, and recovered $\mathrm{TiO}_{2} / \mathrm{SiO}_{2}$ within a $200-800 \mathrm{~nm}$ range. Upon comparing the UV absorption curves of $\mathrm{TiO}_{2}$ and $\mathrm{TiO}_{2} / \mathrm{SiO}_{2}$, we observed that the peak UV light absorption occurred at approximately $350 \mathrm{~nm}$ for both. However, $\mathrm{TiO}_{2} / \mathrm{SiO}_{2}$ had a stronger optical response to UV light, and the absorption band was shifted to the long-wave direction.

The band gap energy was calculated as described in previous studies (Liu et al. 2018, Sun et al. 2013, Zhou et al. 2011):

$$
(\alpha h v)^{\mathrm{n}}=\mathrm{B}(\mathrm{hv}-\mathrm{Eg})
$$


where hv is the photon energy, Eg is the optical band gap of the semi-conductor, $\alpha$ is the absorption coefficient obtained from the scattering and reflection spectra according to Kubelka-Munk theory, B is the proportionality constant, and the value of $n$ depends on the semi-conductor, as well as the type of transition. Fig. 7(b) shows the band gap energy of $\mathrm{TiO}_{2}$, recovered $\mathrm{TiO}_{2}, \mathrm{TiO}_{2} / \mathrm{SiO}_{2}$, and recovered $\mathrm{TiO}_{2} / \mathrm{SiO}_{2}$. As illustrated in the figure, the band gap energy of $\mathrm{TiO}_{2}$ was $3.17 \mathrm{eV}$, whereas the band gap energy of $\mathrm{TiO}_{2} / \mathrm{SiO}_{2}$ was approximately $2.88 \mathrm{eV}$, which was consistent with previous results. The band gap energy of $\mathrm{TiO}_{2}$ and $\mathrm{TiO}_{2} / \mathrm{SiO}_{2}$ increased slightly after use, and the increase in band gap energy indicated that the energy required for the electron transition also increased. This weakened UV light absorption and light utilization ability, and ultimately decreased the catalytic ability of the catalysts, which was consistent with the theory of UV absorption (Zhou et al. 2017).

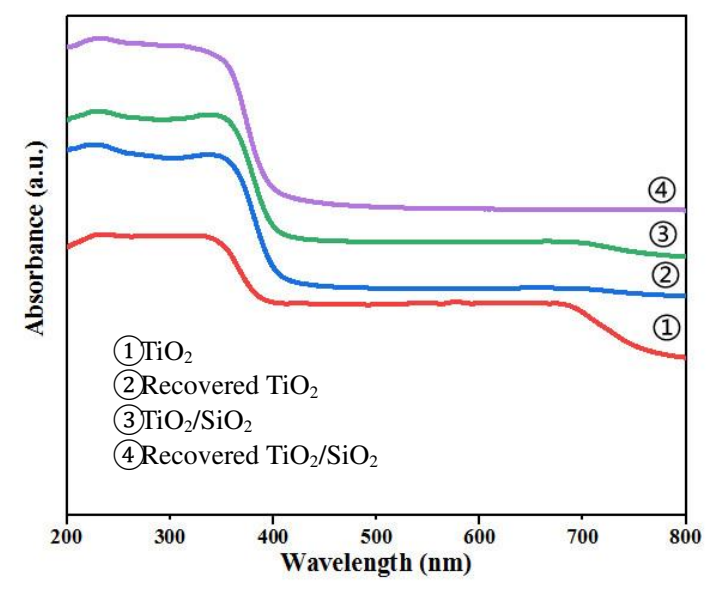

(a)

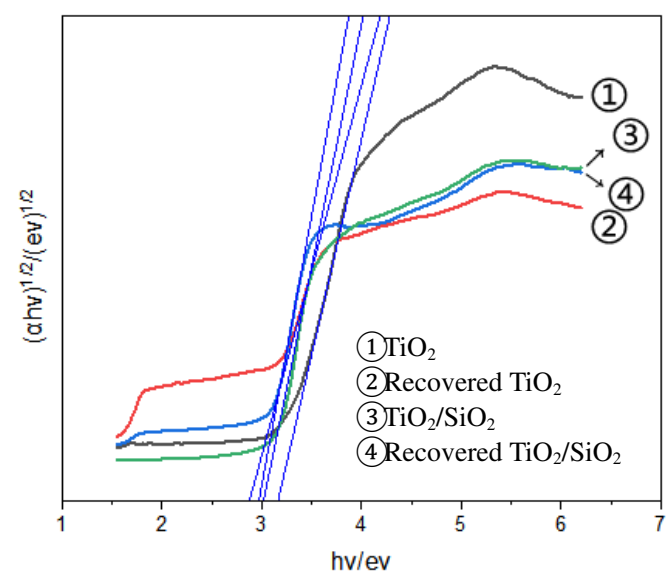

(b)

Fig. 5 (a) UV-Vis DRS spectra of $\mathrm{TiO}_{2}$, recovered $\mathrm{TiO}_{2}, \mathrm{TiO}_{2} / \mathrm{SiO}_{2}$, and recovered $\mathrm{TiO}_{2} / \mathrm{SiO}_{2}$ at $200-800 \mathrm{~nm}$; (b) band gap energy evaluated by the Kubelka-Munk equation

\subsection{Effects of different factors on $\mathrm{N}-\mathrm{NO}_{3}^{-}$removal rates}

To investigate the influence of key factors on the removal rate of nitrates, two different gradients of each factor were selected for the orthogonal test, and the results are summarized in Table 2. The influencing factors exhibited the following order: $\mathrm{N}-\mathrm{NO}_{3}{ }^{-}$concentration $>\mathrm{TiO}_{2}$ dose $>$ formic acid dose. A gradient test was then conducted according to the degree of influence of each factor. 
Table 2. Results of orthogonal tests of $\mathrm{N}^{-\mathrm{NO}_{3}}{ }^{-}$degradation catalyzed by $\mathrm{TiO}_{2}$

\begin{tabular}{|c|c|c|c|c|}
\hline Sample No. & $\begin{array}{c}\text { Nitrate nitrogen } \\
\text { concentration }\left(\mathrm{mg} \cdot \mathrm{L}^{-1}\right)\end{array}$ & $\begin{array}{l}\text { Formic acid dose } \\
\qquad\left(\mathrm{mL} \cdot \mathrm{L}^{-1}\right)\end{array}$ & $\mathrm{TiO}_{2}$ dose $\left(\mathrm{g} \cdot \mathrm{L}^{-1}\right)$ & $\begin{array}{l}\text { Nitrate nitrogen } \\
\text { removal rate }(\%)\end{array}$ \\
\hline 1 & 50 & 0.5 & 0.5 & 91 \\
\hline 2 & 50 & 1.0 & 1.0 & 93 \\
\hline 3 & 90 & 0.5 & 1.0 & 73 \\
\hline 4 & 90 & 1.0 & 0.5 & 53 \\
\hline Mean $1(\%)$ & 92 & 82 & 72 & \\
\hline Mean $2(\%)$ & 63 & 83 & 73 & \\
\hline Range & 0.29 & 0.09 & 0.11 & \\
\hline
\end{tabular}

3.2.1 Effects of $\mathrm{TiO}_{2}$ dose on the removal of low-concentration $\mathrm{N}^{-\mathrm{NO}_{3}}{ }^{-}$

Fig. 6 shows the effects of $\mathrm{TiO}_{2}$ dose $\left(0.6,0.7,0.8,0.9,1.0\right.$, and $\left.1.1 \mathrm{~g} \cdot \mathrm{L}^{-1}\right)$ on the removal of 30 $\mathrm{mg} \cdot \mathrm{L}^{-1} \mathrm{~N}-\mathrm{NO}_{3}{ }^{-}$(formic acid dose $=0.6 \mathrm{~mL} \cdot \mathrm{L}^{-1}, \mathrm{CO}_{2}$ flow rate $=0.1 \mathrm{~m}^{3} \cdot \mathrm{h}^{-1}$ ). As illustrated in Fig. 6, the removal rate of $\mathrm{N}_{-} \mathrm{NO}_{3}{ }^{-}$exhibited an upward and then a downward trend with increasing $\mathrm{TiO}_{2}$ doses. Further, the $\mathrm{N}_{-} \mathrm{NO}_{3}{ }^{-}$removal rate and $\mathrm{N}_{2}$ selectivity in the products reached the highest values $(99.93 \%$ and $81.21 \%$, respectively) when the $\mathrm{TiO}_{2}$ dose was $0.9 \mathrm{~g} \cdot \mathrm{L}^{-1}$. As shown in Fig. 8 (a), the reaction rate reached a maximum at a $\mathrm{TiO}_{2}$ dose of $0.9 \mathrm{~g} \cdot \mathrm{L}^{-1}$.

Theoretically, higher catalyst concentrations should increase the availability of electrons and free radicals and, in turn, $\mathrm{N}_{-} \mathrm{NO}_{3}^{-}$removal rates should continue to increase. However, catalytic performance decreased once the catalyst concentration reached a certain threshold, and similar results have been reported in several previous studies (Baniasadi et al. 2013, Sun et al. 2015). When the catalyst concentration was low, $\mathrm{N}_{-} \mathrm{NO}_{3}{ }^{-}$molecules were not in full contact with it and the catalytic efficiency was low. In contrast, when the catalyst concentration exceeded a critical level, the light transmittance in the solution decreased as the concentration increased, resulting in sub-optimal light utilization and a decrease in catalytic efficiency (Peng et al. 2018, Sun et al. 2015). 

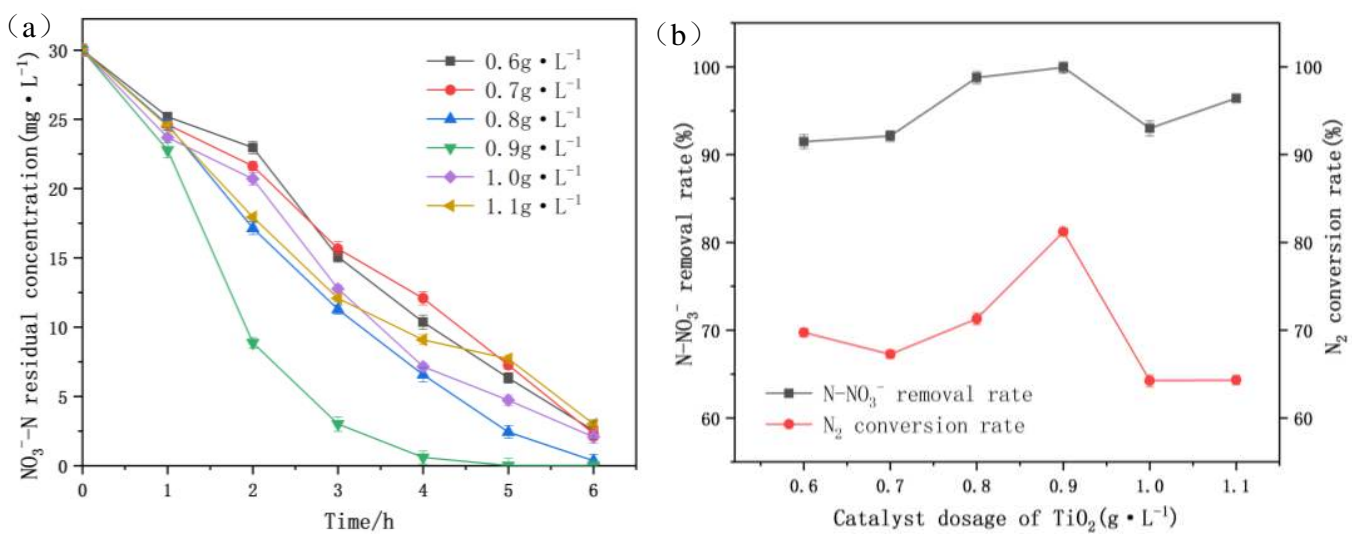

Fig. 6 (a) Effects of $\mathrm{TiO}_{2}$ dose on $\mathrm{N}-\mathrm{NO}_{3}{ }^{-}$photocatalytic reduction as a function of time; (b) effects of catalyst dosage on $\mathrm{N}^{-\mathrm{NO}_{3}}{ }^{-}$removal rate and $\mathrm{N}_{2}$ selectivity in the products

\subsubsection{Effects of formic acid dose on the removal rates of low-concentration $\mathrm{N}_{-} \mathrm{NO}_{3}{ }^{-}$}

In this reaction, formic acid was used as the hole scavenger, and appropriate amounts of formic

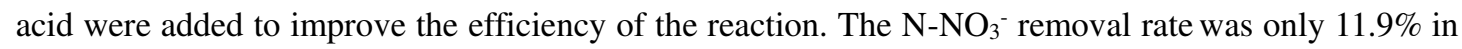
the experimental group without formic acid. Fig. 7 illustrates the effects of formic acid dose $(0.3,0.4$, $0.5,0.6,0.7$, and $\left.0.8 \mathrm{~mL} \cdot \mathrm{L}^{-1}\right)$ on the removal rate of $30 \mathrm{mg} \cdot \mathrm{L}^{-1} \mathrm{~N}^{-N^{-}}{ }_{3}^{-}\left(\mathrm{TiO}_{2}\right.$ dose $=0.9 \mathrm{~g} \cdot \mathrm{L}^{-1}, \mathrm{CO}_{2}$ flow rate $\left.=0.1 \mathrm{~m}^{3} \cdot \mathrm{h}^{-1}\right)$. As shown in Fig. 7 , the $\mathrm{N}^{-\mathrm{NO}_{3}}{ }^{-}$removal rate first increased and then decreased with increasing formic acid concentration, and the $\mathrm{N}_{2}$ selectivity in the products first increased and then stabilized. Further, both the $\mathrm{N}^{-\mathrm{NO}_{3}}{ }^{-}$removal rate and $\mathrm{N}_{2}$ selectivity in the products reached maximum levels (99.93\% and $81.21 \%$, respectively) when the formic acid dose was $0.6 \mathrm{~mL} \cdot \mathrm{L}^{-1}$ [Fig. 7 (a)]. The reaction rate reached its maximum in the first $4 \mathrm{~h}$ and then slowed down as the reactant concentrations decreased.

The role of the hole scavenger in the photocatalytic reactions was to improve photocatalytic efficiency by irreversibly binding to the catalyst surface and preventing complexation with holes. Formic acid, a weak acid, had a weaker adsorption capacity with $\mathrm{TiO}_{2}$ than nitrate ions. Formic acid and holes $\left(\mathrm{h}^{+}\right)$reacted to produce $\cdot \mathrm{CO}_{2}^{-}$, which in turn promoted further $\mathrm{N}_{2}$ production (Chu \&Anastasio 2003, Mack \&Bolton 1999). Catalytic efficiency gradually increased with the addition of formic acid because the complexation of electrons and holes was prevented. However, excessive formic acid addition increased the number of formic acid molecules, and therefore these molecules were more likely to collide with the catalyst surface than the nitrate ions, thus decreasing catalytic efficiency 
279
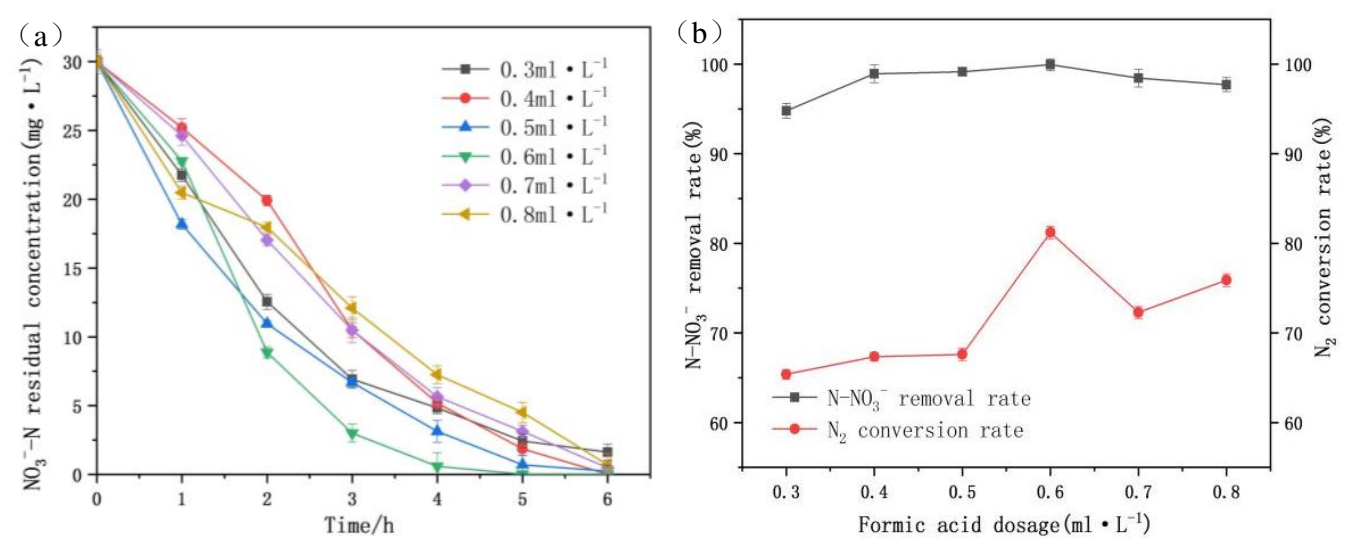

Fig. 7 (a) Effects of formic acid dose on $\mathrm{N}^{-\mathrm{NO}_{3}}{ }^{-}$photocatalytic reduction as a function of time; (b) effects of formic acid dose on $\mathrm{N}-\mathrm{NO}_{3}{ }^{-}$removal rate and $\mathrm{N}_{2}$ selectivity in the products

\subsubsection{Effects of different types of shielding gas on low-concentration $\mathrm{N}-\mathrm{NO}_{3}{ }^{-}$removal rates}

Fig. 8 shows the effects of different types of shielding gas $\left(\mathrm{CO}_{2}, \mathrm{~N}_{2}\right.$, air) on the removal rate of 30 $\mathrm{mg} \cdot \mathrm{L}^{-1} \mathrm{~N}-\mathrm{NO}_{3}{ }^{-}$(formic acid dose $=0.6 \mathrm{~mL} \cdot \mathrm{L}^{-1}, \mathrm{TiO}_{2}$ dose $=0.9 \mathrm{~g} \cdot \mathrm{L}^{-1}$, aeration rate $=0.1 \mathrm{~m}^{3} \cdot \mathrm{h}^{-1}$ ). As

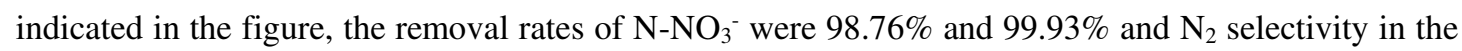
products were $80.14 \%$ and $81.21 \%$ under protection by $\mathrm{N}_{2}$ and $\mathrm{CO}_{2}$, respectively, indicating that $\mathrm{CO}_{2}$ was superior to $\mathrm{N}_{2}$ in this case, although the difference was relatively subtle.

Nitrate removal is a reduction reaction, and shielding gas is introduced to remove dissolved oxygen from water and create a reduction environment in the closed reactor. Interestingly, the results of the air aeration experiment confirmed this notion. $\mathrm{CO}_{2}$ is more effective than $\mathrm{N}_{2}$ because the $\mathrm{pH}$ of the $\mathrm{N}_{2}$-aerated solution is close to neutral under this reaction condition, whereas $\mathrm{CO}_{2}$ dissolved in water can produce $\mathrm{H}^{+}$. Photocatalytic reduction of nitrates requires the consumption of $\mathrm{H}^{+}$, and therefore this reaction is more effective under weakly acidic conditions (Ren et al. 2015). 

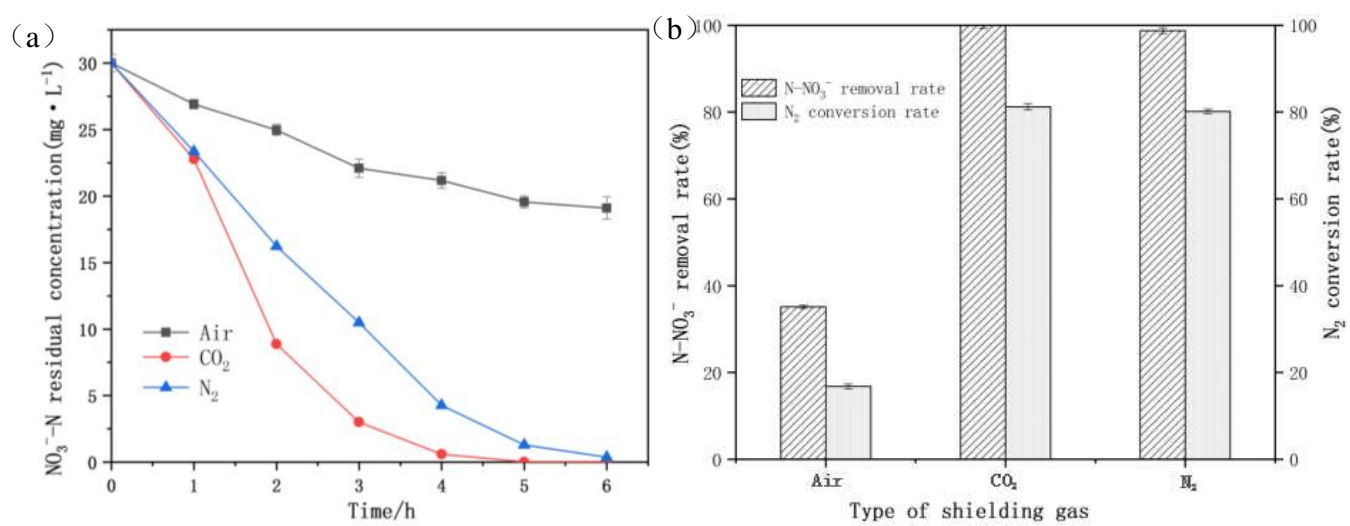

Fig. 8 (a) Effects of type of shielding gas on $\mathrm{N}^{-\mathrm{NO}_{3}}{ }^{-}$photocatalytic reduction as a function of time; (b) effects of type of shielding gas on the $\mathrm{N}_{-} \mathrm{NO}_{3}{ }^{-}$removal rate and $\mathrm{N}_{2}$ selectivity in the products

3.2.4 Effects of $\mathrm{TiO}_{2} / \mathrm{SiO}_{2}$ loading on $\mathrm{N}^{-N}{ }_{3}{ }^{-}$removal rates in low-concentration solutions

Fig. 9 shows the effects of different $\mathrm{TiO}_{2} / \mathrm{SiO}_{2}$ loads $(30 \%, 35 \%, 40 \%, 45 \%, 50 \%)$ on the removal rate of $30 \mathrm{mg} \cdot \mathrm{L}^{-1} \mathrm{~N}^{-\mathrm{NO}_{3}}{ }^{-}$(formic acid dose $=0.6 \mathrm{~mL} \cdot \mathrm{L}^{-1}, \mathrm{TiO}_{2} / \mathrm{SiO}_{2}$ dose $=1.5 \mathrm{~g} \cdot \mathrm{L}^{-1}, \mathrm{CO}_{2}$ flow rate $=$ $\left.0.1 \mathrm{~m}^{3} \cdot \mathrm{h}^{-1}\right)$. As illustrated in Fig. 9, as the loading rate increased from $30 \%$ to $50 \%$, the removal rate of $\mathrm{N}-\mathrm{NO}_{3}{ }^{-}$increased first and then decreased to a relatively stable level. The maximum $\mathrm{N}^{-} \mathrm{NO}_{3}{ }^{-}$removal rate $(78.89 \%)$ was achieved with a $\mathrm{TiO}_{2} / \mathrm{SiO}_{2}$ load of $40 \%$, and the $\mathrm{N}_{2}$ conversion rate was $94.25 \%$

At low loading rates, the amount of $\mathrm{TiO}_{2}$ increased with higher loading rates, thus increasing the number of active sites of the catalyst, as well as the likelihood of contact between nitrate ions and the catalyst. Further, catalytic efficiency also increased at higher loading rates but then decreased with additional loading rate increases after reaching a peak. This was because too much $\mathrm{TiO}_{2}$ accumulated on the $\mathrm{SiO}_{2}$ surface, which was not conducive for dispersion. The specific surface area decreased and catalytic performance also decreased accordingly (Cai et al. 2018). Further, excessively high doping amounts resulted in decreases in the effective active sites in the center, as well as light energy utilization rates and catalytic efficiency. 

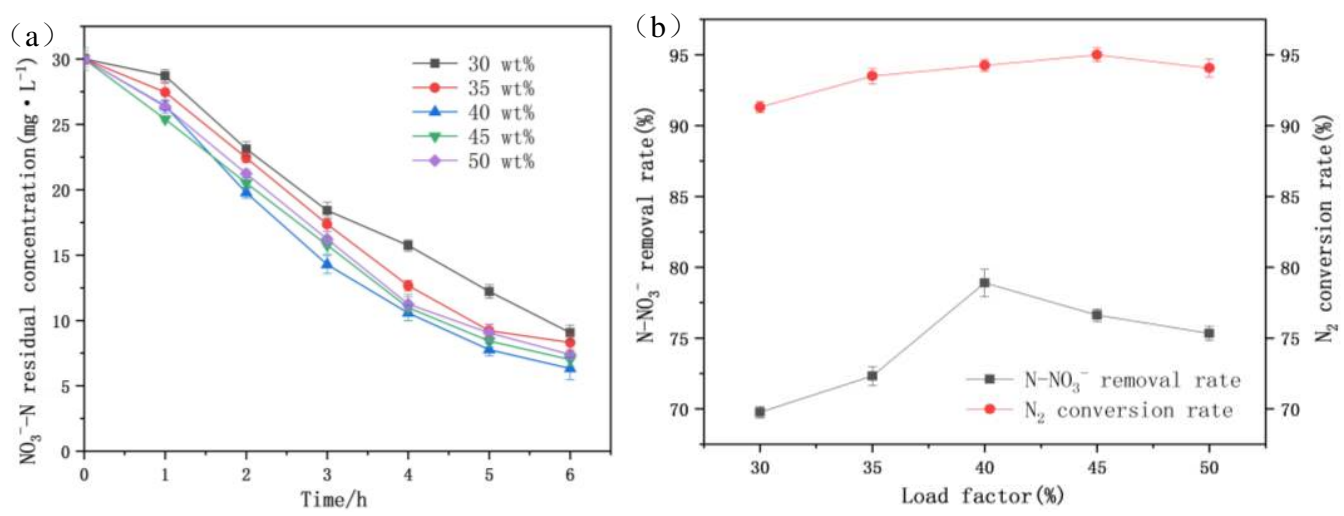

Fig. 9 (a) Effects of $\mathrm{TiO}_{2} / \mathrm{SiO}_{2}$ loading on $\mathrm{N}-\mathrm{NO}_{3}{ }^{-}$photocatalytic reduction as a function of time; (b) effects of

$\mathrm{TiO}_{2} / \mathrm{SiO}_{2}$ on $\mathrm{N}-\mathrm{NO}_{3}{ }^{-}$removal rate and $\mathrm{N}_{2}$ selectivity in the products

\subsubsection{Effects of $\mathrm{TiO}_{2} / \mathrm{SiO}_{2}$ dose on $\mathrm{N}^{-\mathrm{NO}_{3}}{ }^{-}$removal rate in low-concentration solutions}

The effect of different $\mathrm{TiO}_{2} / \mathrm{SiO}_{2}$ composite catalyst doses $\left(1.1,1.2,1.3,1.4,1.5\right.$, and $\left.1.6 \mathrm{~g} \cdot \mathrm{L}^{-1}\right)$ with $40 \%$ loading on the photocatalytic degradation of $30 \mathrm{mg} \cdot \mathrm{L}^{-1} \mathrm{~N}^{-\mathrm{NO}_{3}}{ }^{-}$was investigated at a formic acid dose of $0.6 \mathrm{~mL} \cdot \mathrm{L}^{-1}$ and a $\mathrm{CO}_{2}$ flow rate of $0.1 \mathrm{~m}^{3} \cdot \mathrm{h}^{-1}$. As shown in Fig. 10, the removal rate of $\mathrm{N}-\mathrm{NO}_{3}{ }^{-}$and conversion rate of ammonia nitrogen increased higher $\mathrm{TiO}_{2} / \mathrm{SiO}_{2}$ doses and then decreased after reaching a peak. Both the $\mathrm{N}-\mathrm{NO}_{3}{ }^{-}$removal rate and conversion rate reached a maximum $(83.48 \%$ and $98.80 \%$, respectively) when the $\mathrm{TiO}_{2} / \mathrm{SiO}_{2}$ dose was $1.4 \mathrm{~g} \cdot \mathrm{L}^{-1}$.

The $\mathrm{N}^{-\mathrm{NO}_{3}}{ }^{-}$removal rate and $\mathrm{N}_{2}$ selectivity in the products increased with higher doses due to increases in $\mathrm{TiO}_{2}$ concentrations. Specifically, this increase in the concentration of effective catalysts could improve light utilization, resulting in an excellent removal effect. However, as these doses increased further, the $\mathrm{N}_{-} \mathrm{NO}_{3}{ }^{-}$removal rate and $\mathrm{N}_{2}$ selectivity in the products decreased due to the effect of gravity on $\mathrm{SiO}_{2}$, which caused the deposition of the composite catalyst and reduced light utilization, and therefore catalytic efficiency was slightly decreased (Wang et al. 2021). 

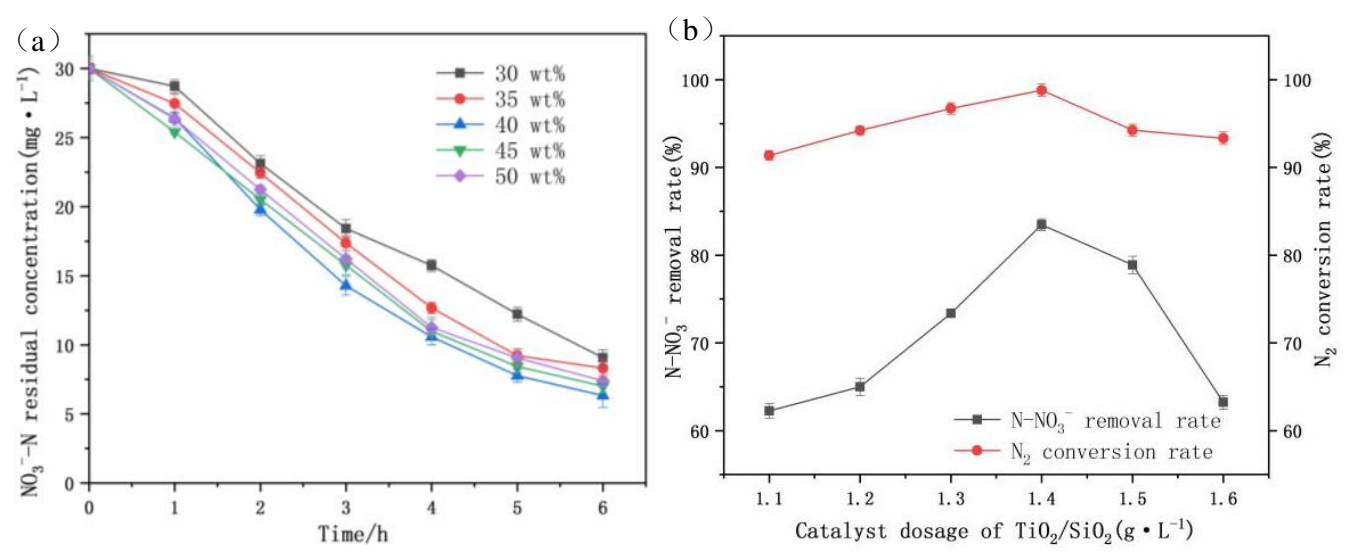

Fig. 10 (a) Effects of $\mathrm{TiO}_{2} / \mathrm{SiO}_{2}$ dose on $\mathrm{N}^{-N^{-}}{ }^{-}$photocatalytic reduction as a function of time; (b) effects of the

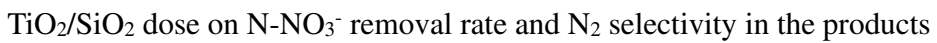

3.3 Sample stability

Catalyst stability is another important parameter to evaluate when assessing catalytic performance. To achieve this, the reacted catalyst was recovered and tested several times under the same conditions. After the reaction, the reaction system was allowed to stand and was then filtered. Our findings indicated that the recovery effect of $\mathrm{TiO}_{2} / \mathrm{SiO}_{2}$ was superior to that of $\mathrm{TiO}_{2}$. The filtered catalyst was repeatedly washed with water and dried in an oven at $60{ }^{\circ} \mathrm{C}$ for reuse. Under optimal conditions (initial $\mathrm{N}-\mathrm{NO}_{3}{ }^{-}$concentration of $30 \mathrm{mg} \cdot \mathrm{L}^{-1}$, formic acid dose of $0.6 \mathrm{~mL} \cdot \mathrm{L}^{-1}, \mathrm{CO}_{2}$ flow rate of $0.1 \mathrm{~m}^{3} \cdot \mathrm{h}^{-1}, \mathrm{TiO}_{2}$ dose of $0.9 \mathrm{~g} \cdot \mathrm{L}^{-1}, 40 \mathrm{wt} \% \mathrm{TiO}_{2} / \mathrm{SiO}_{2}$ dose of $1.4 \mathrm{~g} \cdot \mathrm{L}^{-1}$ ) The experiments were repeated three times and the results are shown in Fig. 11. The catalytic efficiency of the two catalysts decreased after reapplication, indicating that the photocatalytic performance of the used catalysts was reduced. Further, the particle size of both catalysts increased after use, which affected light utilization and decreased catalytic efficiency. The difference in the catalytic efficiency of $\mathrm{TiO}_{2}$ from $99.93 \%$ in the first use cycle to $72.38 \%$ in the second cycle was very significant, whereas the difference between the third and fourth cycles was not significant, both of which accounted for approximately $65 \%$ of the removal efficiency of the first cycle. This was because $\mathrm{TiO}_{2}$ tended to agglomerate after use, which reduced its specific surface area and catalytic efficiency. The catalytic efficiency of $\mathrm{TiO}_{2} / \mathrm{SiO}_{2}$ decreased from $83.48 \%$ in the first cycle to $76.43 \%$ in the second cycle. Similar to $\mathrm{TiO}_{2}$, the difference in the removal rate between the third and fourth cycles was not significant, both of which accounted for approximately $73 \%$ of the removal efficiency of the first cycle. Given that $\mathrm{TiO}_{2}$ and $\mathrm{SiO}_{2}$ were only physically bound, repeated washing would cause some of $\mathrm{TiO}_{2}$ to fall off from $\mathrm{SiO}_{2}$, thus decreasing the effective catalyst 

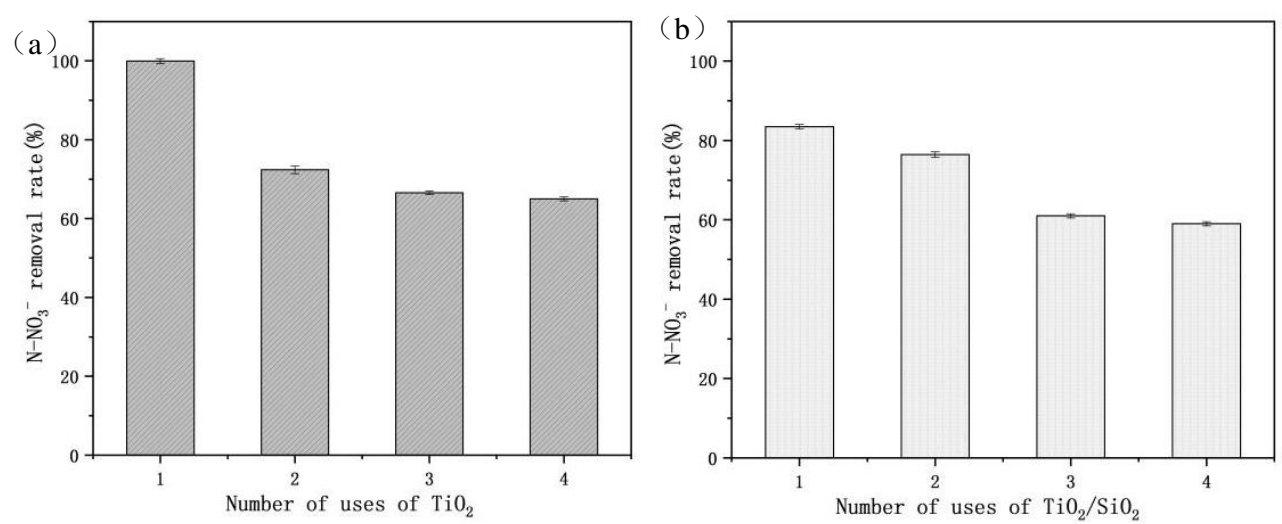

Fig. 11 (a) Effect of the number of $\mathrm{TiO}_{2}$ utilization cycles on $\mathrm{N}^{-N}{ }_{3}{ }^{-}$removal rates; (b) effect of the number of

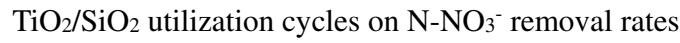

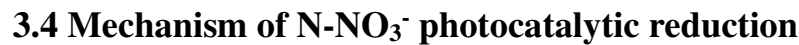

\subsubsection{Kinetics of photocatalytic reduction of nitrates}

In photocatalysis studies, the kinetics of photocatalytic reactions are commonly analyzed by the Langmuir-Hinshelwood kinetic equations:

$$
\mathrm{r}=\frac{1}{\mathrm{~V}} \frac{d C}{d t}=\frac{\mathrm{kC}}{1+(k C)^{2}}
$$

Given that the reaction kinetics of the photocatalytic reduction of nitrates follows the first-order reaction kinetic model, the Langmuir-Hinshelwood kinetic equation can be changed as follows:

$$
\ln \frac{\mathrm{c}}{\mathrm{c}_{0}}=-\mathrm{kt}
$$

where $\mathrm{C}_{0}$ refers to the initial concentration of ammonia nitrogen in the solution, $\mathrm{C}$ refers to the concentration of ammonia nitrogen at any given moment, and $\mathrm{k}$ refers to the kinetic constant.

As shown in Fig. 12, the concentration of nitrates was linearly related to the reaction time, and the correlation coefficients of $\mathrm{TiO}_{2}$ and $\mathrm{TiO}_{2} / \mathrm{SiO}_{2}$ reached 0.95 and 0.99 , respectively, indicating that the

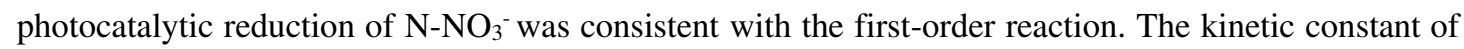
$\mathrm{TiO}_{2}$ was 4.4 times higher than that of $\mathrm{TiO}_{2} / \mathrm{SiO}_{2}$. Therefore, $\mathrm{TiO}_{2}$ was more effective than $\mathrm{TiO}_{2} / \mathrm{SiO}_{2}$ for the photocatalytic reduction of nitrates. Nevertheless, $\mathrm{TiO}_{2} / \mathrm{SiO}_{2}$ had a higher $\mathrm{N}_{2}$ selectivity and 


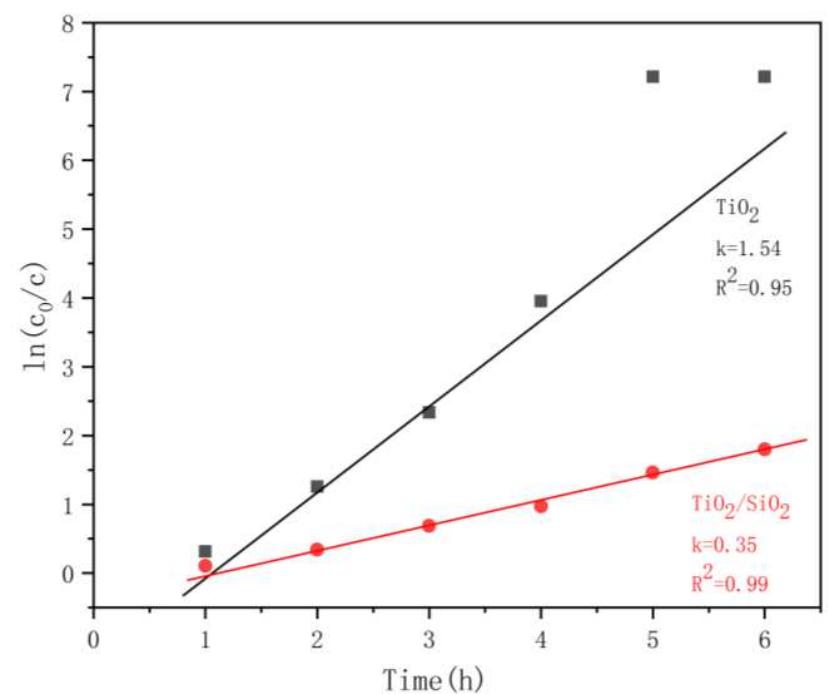

Fig. 12 First-order kinetic model of the photocatalytic oxidation of ammonia nitrogen by $\mathrm{TiO}_{2}$ and

$$
\mathrm{TiO}_{2} / \mathrm{SiO}_{2}
$$

\subsubsection{Mechanism of photocatalytic reduction of nitrates}

Based on the results of this study and previous studies of photocatalysis by $\mathrm{TiO}_{2}$, we proposed the potential mechanisms of photocatalytic reduction of $\mathrm{N}_{-} \mathrm{NO}_{3}{ }^{-}$by $\mathrm{TiO}_{2}$ (Fig. 13).

$\mathrm{TiO}_{2}$ had a low-energy valence band and a high-energy conduction band, which were discontinuous and separated by a band gap. The electrons occupied the low-energy valence band and the high-energy conduction band was empty. When the incident light intensity was greater than or equal to the width of the band gap, the excited electrons in the valence band migrated to the conduction band, generating negatively charged electrons $\left(\mathrm{e}^{-}\right)$in the conduction band and a hole $\left(\mathrm{h}^{+}\right)$in the valence band (Pawar et al. 2018). The photogenerated electrons and holes were separated by an electric field and migrated to the catalyst surface, where the holes $\left(\mathrm{h}^{+}\right)$combined with the formic acid on the catalyst surface to generate free radicals $\left(\cdot \mathrm{CO}_{2}{ }^{-}\right)$. The photogenerated electrons and $\cdot \mathrm{CO}_{2}{ }^{-}$were highly reductive and contributed to the degradation of $\mathrm{N}^{-\mathrm{NO}_{3}}{ }^{-}$and the further conversion of intermediates to $\mathrm{N}_{2}(\mathrm{Chu}$ \&Anastasio 2003, Mack \&Bolton 1999). $\mathrm{NO}_{3}{ }^{-}$was reduced to $\mathrm{N}_{2}$ and $\mathrm{NO}_{2}{ }^{-}$(Eqs. 3.4.2-3-3.4.2-4) on the catalyst surface by the photogenerated electrons and $\cdot \mathrm{CO}_{2}{ }^{-}$, and $\mathrm{NO}_{2}{ }^{-}$on the catalyst surface was reduced to $\mathrm{N}_{2}(\mathrm{Eq} 3.4 .2-5)$ or $\mathrm{NH}_{4}{ }^{+}(\mathrm{Eq} 3.4 .2-6)$ in the presence of photogenerated electrons and $\cdot \mathrm{CO}_{2}{ }^{-}$ (Wang et al. 2021). The main product of the reaction was $\mathrm{N}_{2}$, whereas $\mathrm{NO}_{2}{ }^{-}$and $\mathrm{NH}_{4}{ }^{+}$were produced in 


$$
\begin{gathered}
h v+\mathrm{TiO}_{2} \rightarrow e^{-}+h^{+} \\
\mathrm{HCOO}^{-}+h^{+} \rightarrow \mathrm{CO}_{2}^{-}+\mathrm{H}^{+} \\
\mathrm{NO}_{3}^{-}+2 e^{-}+2 \mathrm{H}^{+} \rightarrow \mathrm{NO}_{2}^{-}+\mathrm{H}_{2} \mathrm{O} \\
\mathrm{NO}_{3}^{-}+2 \cdot \mathrm{CO}_{2}^{-}+2 \mathrm{H}^{+} \rightarrow \mathrm{NO}_{2}^{-}+\mathrm{CO}_{2}+\mathrm{H}_{2} \mathrm{O} \\
2 \mathrm{NO}_{3}^{-}+10 e^{-}+12 \mathrm{H}^{+} \rightarrow \mathrm{N}_{2}+6 \mathrm{H}_{2} \mathrm{O} \\
2 \mathrm{NO}_{3}^{-}+10 \cdot \mathrm{CO}_{2}^{-}+12 \mathrm{H}^{+} \rightarrow \mathrm{N}_{2}+10 \mathrm{CO}_{2}+6 \mathrm{H}_{2} \mathrm{O} \\
2 \mathrm{NO}_{2}^{-}+6 e^{-}+8 \mathrm{H}^{+} \rightarrow \mathrm{N}_{2}+4 \mathrm{H}_{2} \mathrm{O} \\
2 \mathrm{NO}_{2}^{-}+6 \cdot \mathrm{CO}_{2}^{-}+8 \mathrm{H}^{+} \rightarrow \mathrm{N}_{2}+6 \mathrm{CO}_{2}+4 \mathrm{H}_{2} \mathrm{O} \\
2 \mathrm{NO}_{2}^{-}+6 e^{-}+8 \mathrm{H}^{+} \rightarrow \mathrm{NH}_{4}^{+}+4 \mathrm{H}_{2} \mathrm{O} \\
\mathrm{NO}_{2}^{-}+6 \cdot \mathrm{CO}_{2}^{-}+8 \mathrm{H}^{+} \rightarrow \mathrm{NH}_{4}^{+}+6 \mathrm{CO}_{2}+4 \mathrm{H}_{2} \mathrm{O}
\end{gathered}
$$

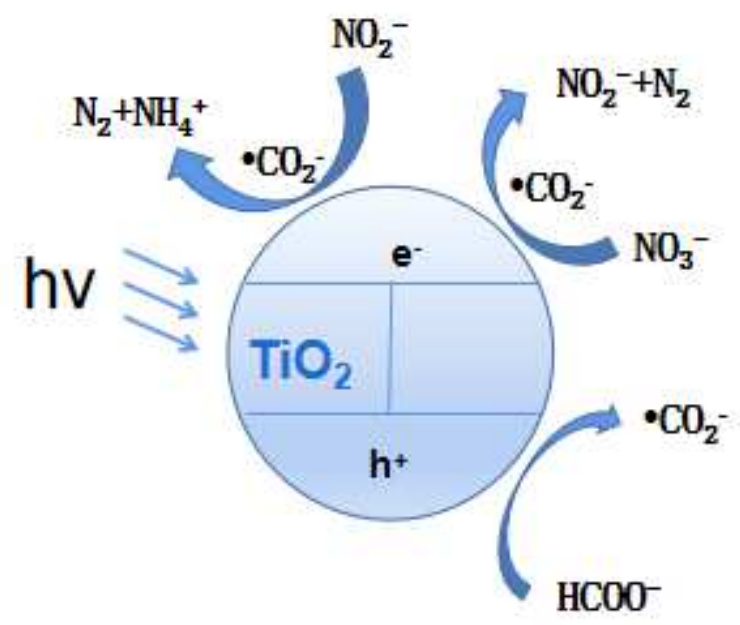

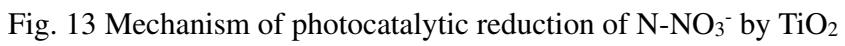

\section{Conclusions}

$\mathrm{TiO}_{2}$ exhibited an excellent effect on the photocatalytic reduction of $\mathrm{N}^{-\mathrm{NO}_{3}}{ }^{-}$in water. However, to enhance its recoverability and recyclability, a $\mathrm{TiO}_{2} / \mathrm{SiO}_{2}$ composite catalyst was prepared by loading $\mathrm{TiO}_{2}$ on $\mathrm{SiO}_{2}$. The components in the $\mathrm{TiO}_{2} / \mathrm{SiO}_{2}$ composite catalyst were evenly distributed, and the 
two were mainly physically bound. This composite catalyst exhibited smaller $\mathrm{TiO}_{2}$ particles on its

409 surface, which increased its specific surface area and improved light utilization. After the conjugation

410 of these two agents, their structure remained largely unchanged; however, the adsorption of the

411 reactants resulted in a larger crystal size, which reduced the catalytic performance. Further, the recovery test demonstrated that the catalyst stability could still be further improved.

414 more effective in treating medium-concentration $\mathrm{N}-\mathrm{NO}_{3}{ }^{-}$wastewater. Moreover, the selectivity of $\mathrm{N}_{2}$ in 415 the products of $\mathrm{TiO}_{2} / \mathrm{SiO}_{2}$ was higher than that of $\mathrm{TiO}_{2}$. In the photocatalytic reduction of $\mathrm{N}-\mathrm{NO}_{3}{ }^{-}$, both

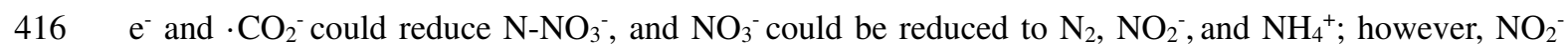
and $\mathrm{NH}_{4}{ }^{+}$occurred in trace amounts, and the final product was mostly $\mathrm{N}_{2}$. 
419 Ethics approval and consent to participate

420 Not applicable.

\section{Consent for publication}

422 Informed consent was obtained from all individual participants included in the study.

423 Availability of data and materials

424 All data generated or analysed during this study are included in this published article [and its

425 supplementary information files].

\section{Competing interests}

427 The authors declare that they have no competing interests.

\section{Authors' contributions}

429 Wanzhen Zhong:Conceptualization, Methodology, Writing - Original Draft.

430 Weizhang Fu*: Supervision, Project administration.

431 Shujuan Sun*: Writing - review \&editing.

432 Lingsheng Wang: Investigation, Software, Resources.

433 Huaihao Liu: Validation, Formal analysis.

434 Junzhi Wang:Data Curation, Visualization.

435 *Weizhang Fu and Shujuan Sun are contributed equally to this work,both corresponding authors.

\section{Acknowledgements}

437 This work was supported by the National Natural Science Foundation [grant number U1906219],

438 Shandong Province major scientific and technological innovation project[grant number

439 2019JZZY010723], Natural Science Foundation of Shandong Province[grant number ZR2020MB087]. 


\section{References}

Baniasadi E, Dincer I, Naterer GF (2013): Measured effects of light intensity and catalyst concentration on photocatalytic hydrogen and oxygen production with zinc sulfide suspensions. International Journal of Hydrogen Energy 38, 9158-9168

Bi X, Du G, Kalam A, Sun D, Zhao W, Yu Y, Su Q, Xu B, Al-Sehemi AG (2021): Constructing anatase $\mathrm{TiO}_{2} /$ Amorphous $\mathrm{Nb}_{2} \mathrm{O}_{5}$ heterostructures to enhance photocatalytic degradation of acetaminophen and nitrogen oxide. Journal of Colloid and Interface Science 601, 346-354

Cai S, Shi S, Li H, Bai Y, Dang D (2018): Construction of self-sufficient Z-scheme $\mathrm{Ag}_{3} \mathrm{PW}_{12} \mathrm{O}_{40} / \mathrm{TiO}_{2}$ photocatalysts for the improved visible-light-driven photo-degradation of rhodamine B. Research on Chemical Intermediates 44

Caswell T, Dlamini MW, Miedziak P, Pattisson S, Davies P, Taylor S, Hutchings G (2020): Enhancement in the rate of nitrate degradation on $\mathrm{Au}$ - and $\mathrm{Ag}$-decorated $\mathrm{TiO}_{2}$ photocatalysts. Catalysis Science \& Technology 10

Chu L, Anastasio C (2003): Quantum Yields of Hydroxyl Radical and Nitrogen Dioxide from the Photolysis of Nitrate on Ice. The Journal of Physical Chemistry A 107, 9594-9602

Doudrick K, Monzon O, Mangonon A, Hristovski K, Westerhoff P (2012): Nitrate Reduction in Water Using Commercial Titanium Dioxide Photocatalysts (P25, P90, and Hombikat UV100). Journal of Environmental Engineering-Asce 138, 852-861

Gao Q, Wang C-Z, Liu S, Hanigan D, Liu S-T, Zhao H-Z (2019): Ultrafiltration membrane microreactor (MMR) for simultaneous removal of nitrate and phosphate from water. Chemical Engineering Journal 355, 238-246

Garcia-Segura S, Lanzarini-Lopes M, Hristovski K, Westerhoff P (2018): Electrocatalytic reduction of nitrate: Fundamentals to full-scale water treatment applications. Applied Catalysis B: Environmental, S0926337318304715

Ghafari S, Hasan M, Aroua MK (2008): Bio-electrochemical removal of nitrate from water and wastewater-A review. Bioresource Technology 99, 3965-3974 
Hou Z, Chu J, Liu C, Wang J, Li A, Lin T, François-Xavier CP (2021): High efficient photocatalytic reduction of nitrate to $\mathrm{N}_{2}$ by Core-shell $\mathrm{Ag} / \mathrm{SiO}_{2} @ \mathrm{cTiO}_{2}$ with synergistic effect of light scattering and surface plasmon resonance. Chemical Engineering Journal 415, 128863

Jesus MAML, Ferreira AM, Lima LFS, Batista GF, Mambrini RV, Mohallem NDS (2021): Micro-mesoporous $\mathrm{TiO}_{2} / \mathrm{SiO}_{2}$ nanocomposites: Sol-gel synthesis, characterization, and enhanced photodegradation of quinoline. Ceramics International 47, 23844-23850

Li H, Cai S, Yang P, Bai Y, Dang D (2018): The synergistic effect of phase heterojunction and surface heterojunction to improve photocatalytic activity of $\mathrm{VO} \bullet-\mathrm{TiO}_{2}$ : the co-catalytic effect of $\mathrm{H}_{3} \mathrm{PW}_{12} \mathrm{O}_{40}$. Journal of Nanoparticle Research 20

Li X, Xiong J, Xu Y, Feng Z, Huang J (2019): Defect-assisted surface modification enhances the visible light photocatalytic performance of $\mathrm{g}-\mathrm{C}_{3} \mathrm{~N}_{4} @ \mathrm{C}-\mathrm{TiO}_{2}$ direct $\mathrm{Z}$-scheme heterojunctions. Chinese Journal of Catalysis 40, 424-433

Li X, Wang S, An H, Dong G, Feng J, Wei T, Ren Y, Ma J (2021): Enhanced photocatalytic reduction of nitrate enabled by Fe-doped $\mathrm{LiNbO}_{3}$ materials in water: Performance and mechanism. Applied Surface Science 539, 148257

Liu W-X, Zhu X-L, Liu S-Q, Gu Q-Q, Meng Z-D (2018): Near-Infrared-Driven Selective Photocatalytic Removal of Ammonia Based on Valence Band Recognition of an $\alpha-\mathrm{MnO}_{2} / \mathrm{N}-$ Doped Graphene Hybrid Catalyst. ACS Omega 3, 5537-5546

Liu X, Liu H, Wang Y, Yang W, Yu Y (2021): Nitrogen-rich g- $\mathrm{C}_{3} \mathrm{~N}_{4} @ \mathrm{AgPd}$ Mott-Schottky heterojunction boosts photocatalytic hydrogen production from water and tandem reduction of $\mathrm{NO}_{3}{ }^{-}$and $\mathrm{NO}_{2}{ }^{-}$. Journal of Colloid and Interface Science 581, 619-626

Lucchetti R, Siciliano A, Clarizia L, Russo D, Di Somma I, Natale F, Guida M, Andreozzi R, Marotta R (2017): Sacrificial photocatalysis: removal of nitrate and hydrogen production by nano-copper-loaded P25 titania. A kinetic and ecotoxicological assessment. Environmental Science and Pollution Research 24 
Lv T, Wang H, Hong W, Wang P, Jia L (2019): In situ self-assembly synthesis of sandwich-like $\mathrm{TiO}_{2} /$ reduced graphene oxide/ $\mathrm{LaFeO}_{3} \mathrm{Z}$-scheme ternary heterostructure towards enhanced photocatalytic hydrogen production. Molecular Catalysis 475, 110497

Mack J, Bolton JR (1999): Photochemistry of nitrite and nitrate in aqueous solution: a review. Journal of Photochemistry and Photobiology A: Chemistry 128, 1-13

Najafidoust A, Haghighi M, Abbasi Asl E, Bananifard H (2019): Sono-solvothermal design of nanostructured flowerlike BiOI photocatalyst over silica-aerogel with enhanced solar-light-driven property for degradation of organic dyes. Separation and Purification Technology 221, 101-113

Nguyen V-C, Nguyen T-V (2009): Photocatalytic decomposition of phenol over $\mathrm{N}-\mathrm{TiO}_{2}-\mathrm{SiO}_{2}$ catalyst under natural sunlight. Journal of Experimental Nanoscience 4, 233-242

Pawar M, Sendoğdular ST, Gouma P, Cozzoli PD (2018): A Brief Overview of $\mathrm{TiO}_{2}$ Photocatalyst for Organic Dye Remediation: Case Study of Reaction Mechanisms Involved in $\mathrm{Ce}-\mathrm{TiO}_{2}$ Photocatalysts System. 2018, 13

Peng X, Wang M, Hu F, Qiu F, Zhang T, Dai H, Cao Z (2018): Multipath fabrication of hierarchical $\mathrm{CuAl}$ layered double hydroxide/carbon fiber composites for the degradation of ammonia nitrogen. Journal of environmental management 220, 173-182

Ren H, Jia S-Y, Zou J-J, Wu S-H, Han X (2015): A facile preparation of $\mathrm{Ag}_{2} \mathrm{O} / \mathrm{P} 25$ photocatalyst for selective reduction of nitrate. Applied Catalysis B: Environmental 176

Satayeva AR, Howell CA, Korobeinyk AV, Jandosov J, Inglezakis VJ, Mansurov ZA, Mikhalovsky SV (2018): Investigation of rice husk derived activated carbon for removal of nitrate contamination from water. Science of The Total Environment 630, 1237-1245

Sun D, Sun W, Yang W, Li Q, Shang JK (2015): Efficient photocatalytic removal of aqueous $\mathrm{NH}_{4}{ }^{+}-\mathrm{NH}_{3}$ by palladium-modified nitrogen-doped titanium oxide nanoparticles under visible light illumination, even in weak alkaline solutions. Chemical Engineering Journal 264, $728-734$ 
Sun H, Zhou G, Liu S, Ang HM, Tadé MO, Wang S (2013): Visible light responsive titania photocatalysts codoped by nitrogen and metal ( $\mathrm{Fe}, \mathrm{Ni}, \mathrm{Ag}$, or $\mathrm{Pt}$ ) for remediation of aqueous pollutants. Chemical Engineering Journal 231, 18-25

Takari A, Ghasemi AR, Hamadanian M, Sarafrazi M, Najafidoust A (2021): Molecular dynamics simulation and thermo-mechanical characterization for optimization of three-phase epoxy/ $\mathrm{TiO}_{2} / \mathrm{SiO}_{2}$ nano-composites. Polymer Testing 93, 106890

Tsang CHA, Li K, Zeng Y, Zhao W, Zhang T, Zhan Y, Xie R, Leung DYC, Huang H (2019): Titanium oxide based photocatalytic materials development and their role of in the air pollutants degradation: Overview and forecast. Environment International 125, 200-228

Tugaoen HON, Garcia-Segura S, Hristovski K, Westerhoff PJSoTTE (2017): Challenges in photocatalytic reduction of nitrate as a water treatment technology. s 599-600, 1524-1551

Velu M, Balasubramanian B, Velmurugan P, Kamyab H, Ravi AV, Chelliapan S, Lee CT, Palaniyappan J (2021): Fabrication of nanocomposites mediated from aluminium nanoparticles/Moringa oleifera gum activated carbon for effective photocatalytic removal of nitrate and phosphate in aqueous solution. Journal of Cleaner Production 281, 124553

Wang B, An B, Su Z, Li L, Liu Y (2021): A novel strategy for sequential reduction of nitrate into nitrogen by $\mathrm{CO}_{2}$ anion radical: Experimental study and DFT calculation. Chemosphere 269, 128754

Wang L, Fu W, Zhuge Y, Wang J, Yao F, Zhong W, Ge X (2021): Synthesis of polyoxometalates $(\mathrm{POM}) / \mathrm{TiO}_{2} / \mathrm{Cu}$ and removal of nitrate nitrogen in water by photocatalysis. Chemosphere 278 , 130298

Wang Y, Xing Z, Li Z, Wu X, Wang G, Zhou W (2017): Facile synthesis of high-thermostably ordered mesoporous $\mathrm{TiO}_{2} / \mathrm{SiO}_{2}$ nanocomposites: An effective bifunctional candidate for removing arsenic contaminations. Journal of Colloid and Interface Science 485, 32-38

Woottikrai C, Arisa S, Pimluck K, Yothin C (2022): Direct dye wastewater photocatalysis using immobilized titanium dioxide on fixed substrate \%J Chemosphere. 286 
Yang Y, Li X-j, Chen J-t, Wang L-y (2004): Effect of doping mode on the photocatalytic activities of $\mathrm{Mo} / \mathrm{TiO}_{2}$. Journal of Photochemistry and Photobiology A: Chemistry 163, 517-522

Yao F, Fu W, Ge X, Wang L, Wang J, Zhong W (2020): Preparation and characterization of a copper phosphotungstate/titanium dioxide $\left(\mathrm{Cu}-\mathrm{H}_{3} \mathrm{PW}_{12} \mathrm{O}_{40} / \mathrm{TiO}_{2}\right)$ composite and the photocatalytic oxidation of high-concentration ammonia nitrogen. Science of The Total Environment 727, 138425

Yu W, Liu X, Pan L, Li J, Liu J, Zhang J, Li P, Chen C, Sun Z (2014): Enhanced visible light photocatalytic degradation of methylene blue by F-doped $\mathrm{TiO}_{2}$. Applied Surface Science 319, $107-112$

Zhou G, Sun H, Wang S, Ming Ang H, Tadé MO (2011): Titanate supported cobalt catalysts for photochemical oxidation of phenol under visible light irradiations. Separation and Purification Technology 80, 626-634

Zhou G, Shen L, Xing Z, Kou X, Duan S, Fan L, Meng H, Xu Q, Zhang X, Li L, Zhao M, Mi J, Li Z (2017): $\mathrm{Ti}^{3+}$ self-doped mesoporous black $\mathrm{TiO}_{2} /$ graphene assemblies for unpredicted-high solar-driven photocatalytic hydrogen evolution. Journal of Colloid and Interface Science 505, $1031-1038$ 